\title{
Leaf Wilting Movement Can Protect Water-Stressed Cotton (Gossypium hirsutum L.) Plants Against Photoinhibition of Photosynthesis and Maintain Carbon Assimilation in the Field
}

\author{
Ya-Li Zhang $\cdot$ Hong-Zhi Zhang $\cdot$ Ming-Wei Du • \\ Wei Li • Hong-Hai Luo • Wah-Soon Chow • \\ Wang-Feng Zhang
}

Received: 30 October 2009 /Accepted: 13 November 2009/Published online: 4 December 2009

(C) The Botanical Society of Korea 2009

\begin{abstract}
Under severe water stress, leaf wilting is quite general in higher plants. This passive movement can reduce the energy load on a leaf. This paper reports an experimental test of the hypothesis that leaf wilting movement has a protective function that mitigates against photoinhibition of photosynthesis in the field. The experiments exposed cotton (Gossypium hirsutum L.) to two water regimes: waterstressed and well-watered. Leaf wilting movement occurred in water-stressed plants as the water potential decreased to $-4.1 \mathrm{MPa}$, reducing light interception but maintaining comparable quantum yields of photosystem II (PS II; Yield for short) and the proportion of total PS II centers that were open (qP). Predrawn $F_{\mathrm{v}} / F_{\mathrm{m}}$ (potential quantum yield of PS II) as an indicator of overnight recovery of PS II from photoinhibition was higher than or similar to that in wellwatered plants. Compared with water-stressed cotton leaves for which wilting movement was permitted, water-stressed cotton leaves restrained from such movement had significantly increased leaf temperature and instantaneous $\mathrm{CO}_{2}$ assimilation rates in the short term, but reduced Yield, $\mathrm{qP}$, and $F_{\mathrm{v}} / F_{\mathrm{m}}$. In the long term, predrawn $F_{\mathrm{v}} / F_{\mathrm{m}}$ and $\mathrm{CO}_{2}$ assimilation capacity were reduced in water-stressed leaves
\end{abstract}

Y.-L. Zhang • H.-Z. Zhang • M.-W. Du • W. Li • H.-H. Luo •

W.-F. Zhang $(\bowtie)$

The Key Laboratory of Oasis Eco-agriculture,

Xinjiang Production and Construction Group, Shihezi University,

Shihezi 832003, People's Republic of China

e-mail: zwf_shzu@163.com

\section{W.-S. Chow}

Division of Plant Sciences, Research School of Biology,

College of Medicine, Biology and Environment,

Australian National University,

Canberra, ACT 0200, Australia restrained from wilting movement. These results suggest that, under water stress, leaf wilting movement could reduce the incident light on leaves and their heat load, alleviate damage to the photosynthetic apparatus due to photoinhibition, and maintain considerable carbon assimilation capacity in the long term despite a partial loss of instantaneous carbon assimilation in the short term.

Keywords Carbon assimilation · Chlorophyll fluorescence · Leaf wilting movement $\cdot$ Photoprotection · Water stress

\author{
Abbreviations \\ A $\quad \mathrm{CO}_{2}$ assimilation rate (in micromoles of $\mathrm{CO}_{2}$ per \\ square meter per second) \\ $F_{\mathrm{m}} \quad$ maximal chlorophyll fluorescence yield \\ $F_{\mathrm{o}} \quad$ ground chlorophyll fluorescence yield \\ $F_{\mathrm{v}}, F_{\mathrm{v}}{ }^{\prime}$ maximum variable fluorescence in the dark- and \\ light-adapted state, respectively \\ $F_{\mathrm{v}} / F_{\mathrm{m}} \quad$ potential quantum yield of photosystem II \\ $F_{\mathrm{m}}{ }^{\prime} \quad$ maximum light-adapted fluorescence \\ $F_{\mathrm{s}} \quad$ steady-state fluorescence yield during illumination \\ NPQ nonphotochemical quenching \\ PAR photosynthetically active radiation (in micromoles \\ per square meter per second) \\ PS II photosystem II \\ qP photochemical quenching coefficient \\ Yield PS II quantum yield in the light
}

\section{Introduction}

Photoinhibition has an adverse impact on plant growth and productivity (Long et al. 1994). However, plants can 
minimize photoinhibition and avoid photodamage through various morphological adjustments and physiological alterations on shorter or longer time scales (Long et al. 1994). One of the most efficient ways of avoiding excessive light absorption in leguminous species is the active paraheliotropic movement of leaves (Ludlow and Björkman 1984; Kao and Tsai 1998; Pastenes et al. 2005; Arena et al. 2008). However, a photoprotective mechanism of this type is not universal in higher plants.

Water stress often accompanies high light stress in the field. On one hand, water stress limits leaf transpiration, resulting in an increase in leaf temperature, thereby intensifing the photoinhibition of photosynthesis caused by strong irradiation (Powles 1984). On the other hand, water stress lowers the water potential of leaves and the osmotic potential of petiole cells - in extreme cases, the leaves wilt. This passive, drought-induced drooping of leaves may have multiple physiological significance for plants in that it may reduce both water loss from the leaf and the amount of light incident on the leaf surface, the latter lowering the energy load on a leaf (Begg 1980; Chiariello et al. 1987; Björkman and Demming-Adams 1994). Supposedly, the reduced energy load helps to alleviate photoinhibition and to accelerate net recovery. Although such drought-induced drooping of leaves is quite general in higher plants, very few studies, to our knowledge, have provided direct experimental envidence focused on its role in photoprotective mechanisms.

Cotton (Gossypium hirsutum L.) is an important fiber crop worldwide. Under favorable conditions, cotton turns its leaves towards sunlight to maximize light interceptionthe so-called leaf diaheliotropic movement-(Lang 1973; Ehleringer and Hammond 1987), indicating that cotton is a speices acclimatized to high-intensity sunlight. However, under moderate drought, cotton leaves wilt like those of any higher plant, and the diaheliotropic leaf movement disappears. Thus, the present study sought to assess the role of leaf wilting movement in photoprotection in field-grown cotton subjected to water stress.

\section{Materials and Methods}

The experiment was conducted at an experimental field of Shihezi Agricultural College, Shihezi University, Xinjiang, China $\left(45^{\circ} 19^{\prime} \mathrm{N}, 86^{\circ} 03^{\prime} \mathrm{E}\right)$ in 2008. The experimental design was a randomized complete block with three replications with two plots per block. Each plot in a block corresponded to a water regime: well-watered and waterstressed and was $30 \times 3.5 \mathrm{~m}$. Cotton $(G$. hirsutum L. cv. Xinluzao 13) was grown under field conditions with undermulch drip irrigation. Seeds were sown on 24 April 2008 in rows $12 \mathrm{~cm}$ apart and the plant density was $1.8 \times$
$10^{5} \mathrm{ha}^{-1}$. Two water regimes were followed, namely, wellwatered and water-stressed. The well-watered plots were irrigated according to standard local practice, whereas the water-stressed plots were not irrigated after sowing in order to induce the leaves to wilt. As expected, leaves began to wilt in mid-June. Measurements were conducted three times in July and only 1-day data are present here due to similarity of the results. For the measurements, plants in each plot were selected at random and, from each selected plant, the topmost west-facing leaf on the main stem was chosen.

On the day of measurement, when leaves wilted, to eliminate the effect of passive leaf movement caused by wilting, some of them were brought to a horizontal position and retained in that position by sandwiching them between nylon strips in a metal frame, as described by Pastenes et al. (2005). (From now on, these are referred to as stressrestrained leaves. Leaves that were allowed passive wilting movement are referred to as stress-free leaves.) To protect stress-restrained leaves from wind, windbreaks were used around the experimental plot where stress-restrained leaves and stress-free leaves were located.

\section{Environmental Conditions}

Ambient photosynthetically active radiation (PAR) was measured with an external quantum sensor of a Li-6400 infrared gas exchange analyzer (IRGA; Li-Cor Inc., Lincoln, USA) by positioning the sensor perpendicular to the sunlight or horizontal to the ground. Air temperature and relative humidity were measured with a $\mathrm{HOBO}$ hygrothermometer (Onset, USA) $1 \mathrm{~m}$ above the ground.

\section{Leaf Movement}

Leaf movement was measured as a change in the midrib angle using an inclinometer and a protractor. The leaf position and orientation can be determined quantitatively by measuring three separate angles: azimuth angle, lamina angle, and midrib angle, which were described by Ceulemans and Isebrands (1996). Because azimuth angle and lamina angle remained more or less constant, only data on midrib angle are presented here.

\section{Leaf Water Potential}

Leaf water potential was measured with an SKPM 1400 pressure chamber (Skye, UK) four times in a day: at predawn (0600 hours), at midmorning when leaves in the water-stressed plants had wilted (about 1100 hours), at midday (1400 hours), and in late evening (2100 hours). The leaf lamina was enclosed in the chamber and subjected to increasing pressure from a compressed nitrogen cylinder 
until free sap was visible at the petiole outside the chamber. In each treatment, at least four leaves in each plot were chosen at random for measurement.

\section{Chlorophyll Fluorescence}

Chlorophyll fluorescence was measured in diurnal time courses using a portable saturation pulse fluorometer PAM2100 equipped with a 2030-B leaf clip holder (Walz, Effeltrich, Germany). PAR incident on the leaf surface was measured with a microquantum sensor on the leaf clip. Leaf temperatures were recorded simultaneously with a $\mathrm{Ni} / \mathrm{NiCr}$ thermocouple of the leaf clip holder appressed to the underside (abaxial surface) of the leaves. For each treatment, nine to ten individual leaves in each plot were sampled and labeled. Care was taken not to disturb the position of the leaf being measured and its exposure to light. Three measurements were made at different points on each leaf.

Maximal $\left(F_{\mathrm{m}}\right)$ and ground $\left(F_{\mathrm{o}}\right)$ fluorescence yields of dark-adapted leaves were measured at predawn. $F_{\mathrm{o}}$ was obtained with a measuring light of $0.5 \mu \mathrm{mol} \mathrm{m} \mathrm{m}^{-2} \mathrm{~s}^{-1}$ at a frequency of $0.6 \mathrm{kHz}$, while the $F_{\mathrm{m}}$ was measured with a 0.8 -s saturating pulse at $>8,000 \mu \mathrm{mol} \mathrm{m} \mathrm{m}^{-2} \mathrm{~s}^{-1}$. Potential quantum yield of photosystem II (PS II; $F_{\mathrm{v}} / F_{\mathrm{m}}$ ) was calculated, where $F_{\mathrm{v}}$ is the maximum variable fluorescence $\left(F_{\mathrm{v}}=F_{\mathrm{m}}-F_{\mathrm{o}}\right)$. During the diurnal time courses, $F_{\mathrm{s}}$ (fluorescence of the light-adapted leaf) and $F_{\mathrm{m}}{ }^{\prime}$ (the maximum light-adapted fluorescence) were measured. $F_{\mathrm{s}}$ was obtained by setting the measuring light to a frequency of $20 \mathrm{kHz} ; F_{\mathrm{m}}{ }^{\prime}$ was measured with a 0.8 -s saturating pulse at $>8,000 \mu \mathrm{mol} \mathrm{m} \mathrm{m}^{-2}$. PS II quantum yield in the light (Yield) was calculated as $\left(F_{\mathrm{m}}{ }^{\prime}-F_{\mathrm{s}}\right) / F_{\mathrm{m}}{ }^{\prime}$ (Genty et al. 1989). Photochemical quenching coefficient (qP) was calculated as $\left(F_{\mathrm{m}}{ }^{\prime}-F_{\mathrm{s}}\right) /\left(F_{\mathrm{m}}{ }^{\prime}-F_{\mathrm{o}}{ }^{\prime}\right)$ (Krause and Weis 1991). Minimal fluorescence under light exposure $\left(F_{\mathrm{o}}{ }^{\prime}\right)$ was calculated according to Oxborough and Baker (1997) using the equation $F_{\mathrm{o}}{ }^{\prime}=F_{\mathrm{o}} /\left(F_{\mathrm{v}} / F_{\mathrm{m}}+F_{\mathrm{o}} / F_{\mathrm{m}}{ }^{\prime}\right)$. Nonphotochemical quenching (NPQ) was calculated as $\left(F_{\mathrm{m}}-F_{\mathrm{m}}{ }^{\prime}\right) / F_{\mathrm{m}}{ }^{\prime}$, where $F_{\mathrm{m}}$ is the value of the predawn measurements (Bilger and Björkman 1990).

The maximum quantum yield after $30 \mathrm{~min}$ dark adaptation using leaf clips, measured as $F_{\mathrm{v}} / F_{\mathrm{m}}$, was determined by means of a nonmodulated fluorimeter PEA (Hansatech, UK); the leaves were the same as those used for the measurements during the day. For each treatment, at least five leaves in each plot were chosen for measurement. Different leaves were used for the fluorescence quenching parameters and gas exchange parameters in that dark adaptation affect the leaf light exposure status.

After keeping the wilted leaves horizontal for 4 days, predawn $F_{\mathrm{v}} / F_{\mathrm{m}}$ of leaves was determined using PAM 2100 in the case of both stress-free leaves and stress-restrained leaves (those that had been subjected to stress but were maintained in the horizontal position by providing adequate support).

$\mathrm{CO}_{2}$ Assimilation Rate

Leaf $\mathrm{CO}_{2}$ assimilation rate was measured in diurnal time courses using a Li-6400 IRGA. Measurements were done on the same previously labeled leaves used for the fluorescence quenching in the same day, taking care not to disturb the leaf position. Red-blue light (Li-Cor Inc., Lincoln, USA) was used for tracking the PAR incident on leaves measured by 2010-B leaf holder of PAM 2100. Although the effect of light spectrum on photosynthesis needs to be considered, particularly the lack of far-red light present in artificial light, red-blue artificial light sources have been widely used to conduct photosynthesis research.

After keeping the wilted leaves horizontal for 4 days, steady-state leaf $\mathrm{CO}_{2}$ assimilation rates and $C_{\mathrm{i}} / C_{\mathrm{a}}$ of both stress-restrained leaves and stress-free leaves were determined under natural conditions with PAR of $1,000 \mu \mathrm{mol} \mathrm{m}^{-2} \mathrm{~s}^{-1}$ and a leaf temperature of $31-33^{\circ} \mathrm{C}$.

\section{Date Analyses}

Statistical analysis of the data was performed by one-way analysis of variance according to Duncan's multiple range test, based on a significance level of $P<0.05$.

\section{Results}

\section{Climate}

As shown in Fig. 1a, at 0800 hours, PAR measured with the sensor perpendicular to the sun's rays reached $900 \mu \mathrm{mol}$ $\mathrm{m}^{-2} \mathrm{~s}^{-1}$, but was only $250 \mu \mathrm{mol} \mathrm{m} \mathrm{m}^{-2} \mathrm{~s}^{-1}$ when the sensor was horizontal. Both increased rapidly, reaching 2,020 and $1,880 \mu \mathrm{mol} \mathrm{m}^{-2} \mathrm{~s}^{-1}$ at midday, respectively, and decreased in the afternoon. Air temperature rose from $19^{\circ} \mathrm{C}$ early in the morning to $27.5^{\circ} \mathrm{C}$ at midday. At 1800 hours, the air temperature reached the highest value $34^{\circ} \mathrm{C}$ and then fell gradually in the afternoon (Fig. 1b). As expected, relative humidity fell throughout the day as air temperature increased (Fig. 1c).

Leaf Water Potential, Leaf Movement, Light Interception, and Leaf Temperature

Water-stressed plants had a significantly lower predawn water potential than well-watered plants $(-3.4$ and $-0.9 \mathrm{MPa}$ respectively, Fig. 2). During the day, waterstressed plants had consistently lower water potential than 


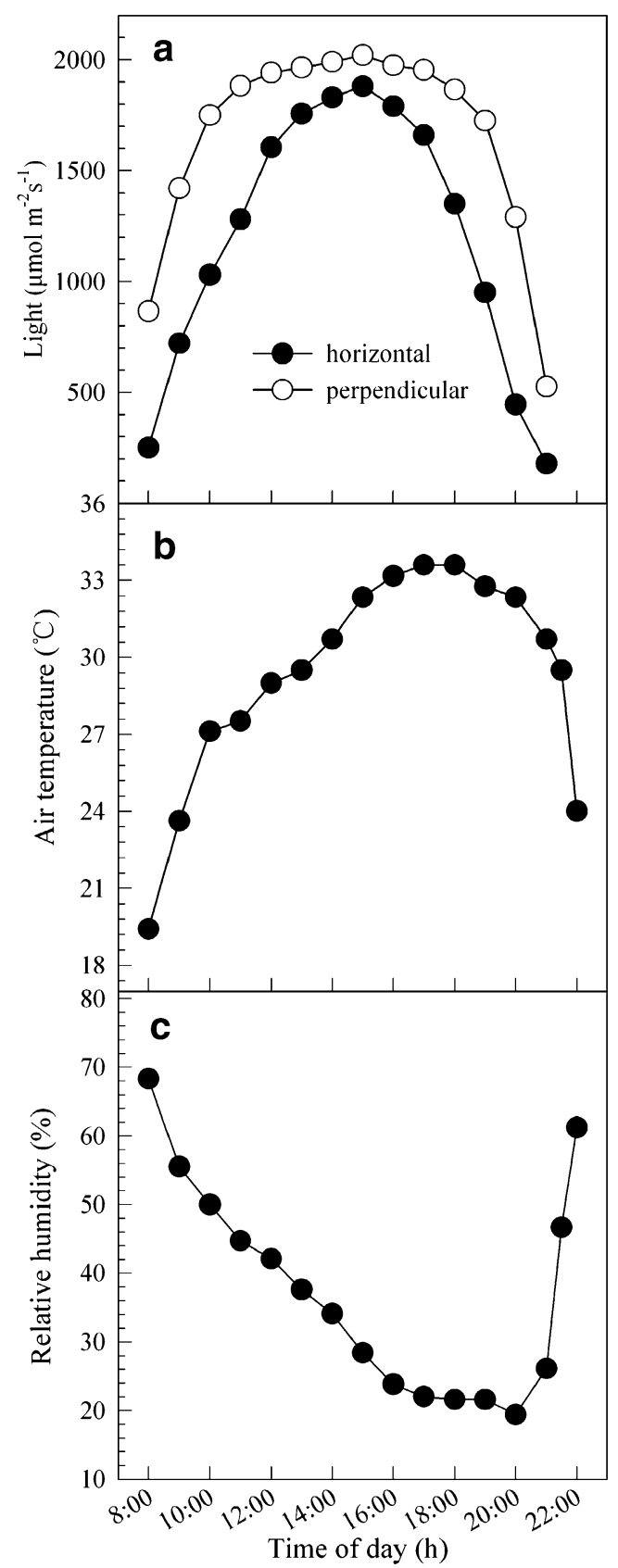

Fig. 1 Diurnal time course of a PAR on a surface horizontal to the ground or perpendicular to sunlight, $\mathbf{b}$ air temperature, and $\mathbf{c}$ relative humidity

well-watered plants. At about 1100 hours, when leaves had wilted in water-stressed plants (Fig. 2), water potential was $-4.1 \mathrm{MPa}$; no difference was observed on water potential between stress-free and stress-restrained leaves.

As shown in Fig. 3, diaheliotropic movement of leaves was observed in the field-grown cotton, which maximized the incident light. Leaves from the water-stressed plants, however, only exhibited diaheliotropic movement in the morning, after which they drooped considerably. As expected, with the increase in sunlight and air temperature, leaf water potential declined further and leaves from the water-stressed plants wilted at about 1100 hours.

Associated with leaf wilting, interception of light by a water-stressed leaf also decreased, as shown by the PAR incident on a leaf (Fig. 4a). Leaf temperature was higher in water-stressed leaves than in well-watered leaves, but wilting without restrained leaf movement ameliorated the temperature rise (Fig. 4b).

\section{Chlorophyll Fluorescence}

As shown in Fig. 5, predawn $F_{\mathrm{v}} / F_{\mathrm{m}}$ values were above 0.8 in water-stressed and well-watered plants. During the day, water-stressed (but unrestrained) leaves had higher or similar $F_{\mathrm{v}} / F_{\mathrm{m}}$ values after 30 min dark adaptation compared to those from well-watered plants. However, stressrestrained leaves had significantly lower $F_{\mathrm{v}} / F_{\mathrm{m}}$ compared to stress-free leaves. By late evening, the $F_{\mathrm{v}} / F_{\mathrm{m}}$ values had recovered to above 0.8 in leaves from all the treatments. Even so, compared to stress-free leaves, the stress-restrained leaves had significantly lower values of $F_{\mathrm{v}} / F_{\mathrm{m}}$.

The diurnal time courses of Yield of PS II photochemistry differed markedly between treatments, which showed the usual inverse relation to PAR (Figs. 4a and 6a). From 0800 to 1000 hours, no significant differences were observed between well-watered and water-stressed plants. When leaves from water-stressed plants wilted (about 1100 hours), the stress-free leaves recorded significantly higher Yield than well-watered leaves did. However, stressrestrained leaves had significantly lower Yield. From midday to afternoon, the stress-free leaves had a consistently higher Yield than that recorded in well-watered plants

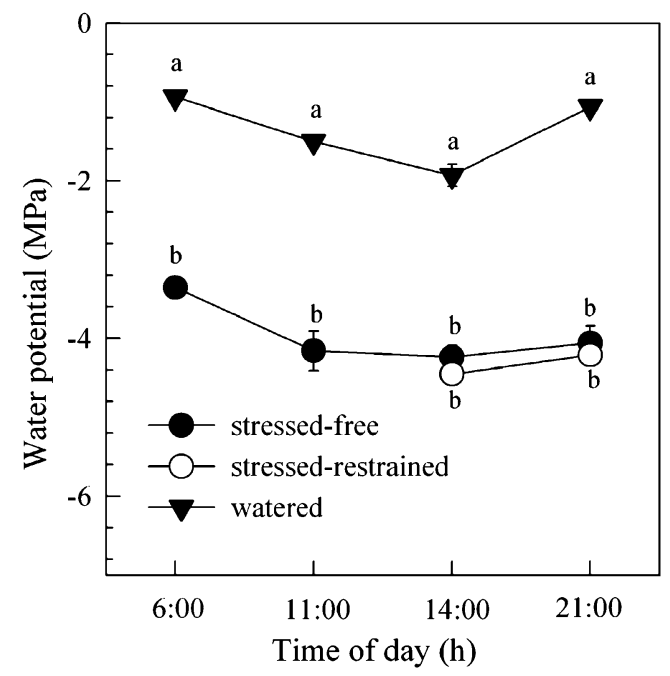

Fig. 2 Diurnal time course of leaf water potential in well-watered leaves, stress-free leaves, and stress-restrained leaves. Different letters indicate differences between treatments at the same time of day at $P<0.05$ according to Duncan's multiple range test. Bars represent the standard error (SE) 


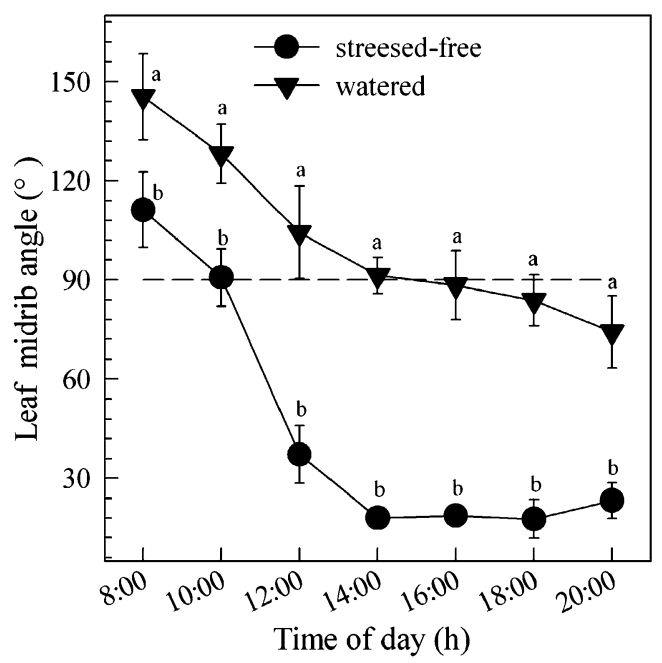

Fig. 3 Diurnal time course of leaf midrib angle in well-watered leaves, and stress-free leaves. Dashed line represents horizontal leaves. Different letters indicate differences between treatments at the same time of day at $P<0.05$ according to Duncan's multiple range test. Bars represent the SE

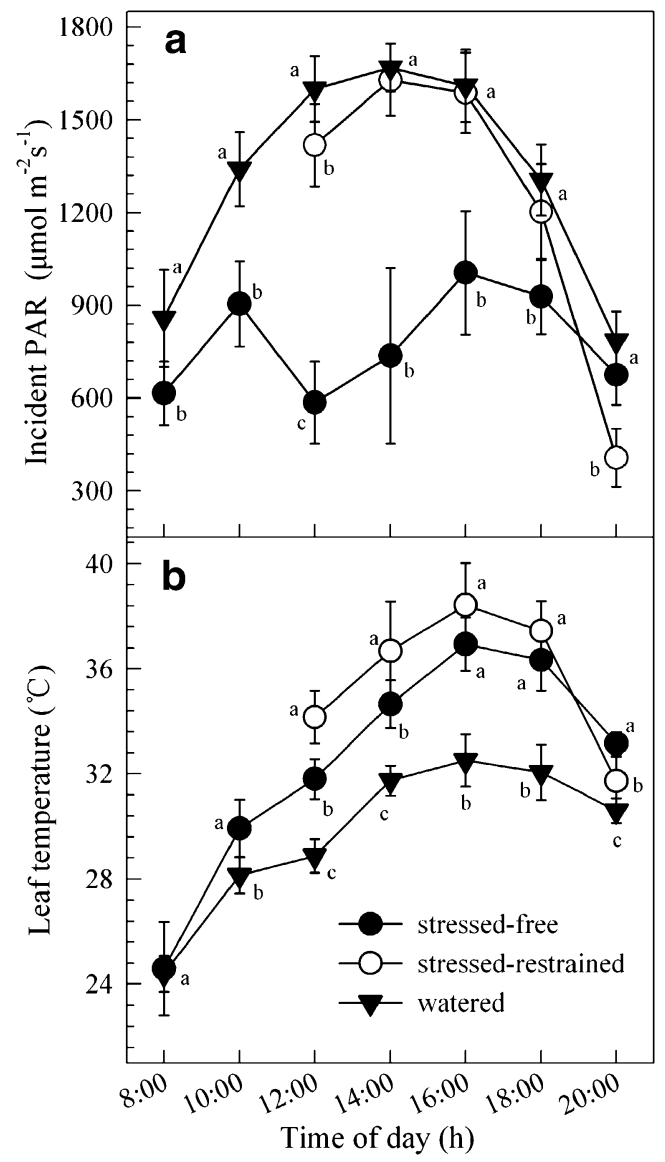

Fig. 4 Diurnal time course of a leaf incident PAR light and $\mathbf{b}$ leaf temperature in well-watered leaves, stress-free leaves, and stressrestrained leaves. Different letters indicate differences between treatments at the same time of day at $P<0.05$ according to Duncan's multiple range test. Bars represent the $\mathrm{SE}$

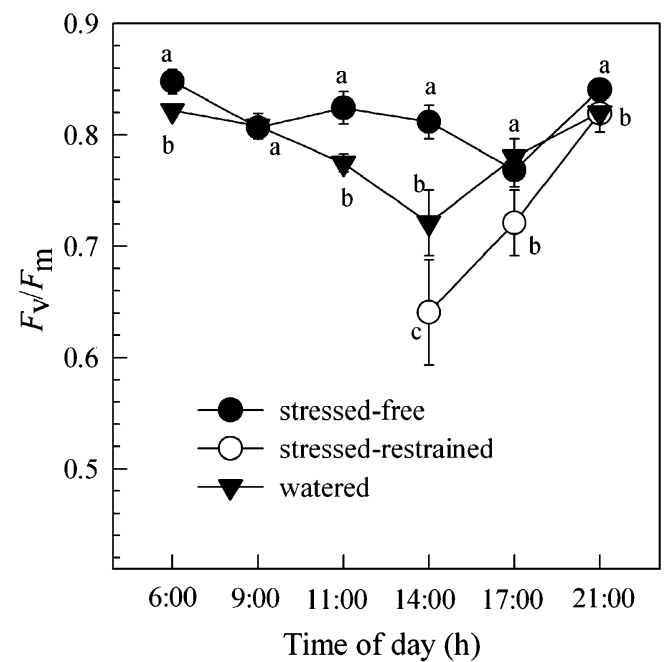

Fig. 5 Diurnal time course of $F_{\mathrm{v}} / F_{\mathrm{m}}$ in well-watered leaves, stressfree leaves, and stress-restrained leaves. Different letters indicate differences between treatments at the same time of day at $P<0.05$ according to Duncan's multiple range test. Bars represent the SE

because more light was incident on the well-watered leaves; both were higher than that recorded in stress-restrained leaves, except at 2000 hours.

As expected, the diurnal time courses of $\mathrm{qP}$ also showed marked differences between treatments (Fig. 6b). The patterns were similar to those shown for Yield and $F_{\mathrm{v}} / F_{\mathrm{m}}$. As shown in Fig. 6c, the diurnal time course of NPQ showed a pattern that followed the PAR incident on leaves with a very clear gradient between treatments. Although the stress-free leaves had received consistently lower incident light compared to leaves from well-watered plants, the free leaves had a higher or similar NPQ during the day, except at 1200 hours. In particular, NPQ was the highest in stressrestrained leaves.

\section{$\mathrm{CO}_{2}$ Assimilation Rate}

Measurements of gas exchange confirmed the expected effects of water deficit on carbon assimilation (Fig. 6d). Leaves from well-watered plants maintained higher $\mathrm{CO}_{2}$ assimilation rates during the day than those from waterstressed plants. In well-watered plants, the diurnal pattern of $\mathrm{CO}_{2}$ assimilation rates followed that of PAR in the morning, but after midday, $\mathrm{CO}_{2}$ assimilation rates began to deline. Leaves from water-stressed plants, however, recorded their hightest $\mathrm{CO}_{2}$ assimilation rates early in the morning, but the rates fell sharply at midday to below $3 \mu \mathrm{mol} \mathrm{CO}_{2} \mathrm{~m}^{-2} \mathrm{~s}^{-1}$. Furthermore, although the PAR incident on leaves declined, $\mathrm{CO}_{2}$ assimilation rates recovered in the stress-free leaves during the afternoon. In the case of stress-restrained leaves, $\mathrm{CO}_{2}$ assimilation rates were significantly higher than those in stress-free leaves except at 1400 and 2000 hours. 
Fig. 6 Diurnal time course of a Yield, b qP, c NPQ, and $\mathbf{d} \mathrm{CO}_{2}$ assimilation rate $A$ in wellwatered leaves, stress-free leaves, and stress-restrained leaves. Different letters indicate differences between treatments at the same time of day at $P<0.05$ according to Duncan's multiple range test. Bars represent the SE

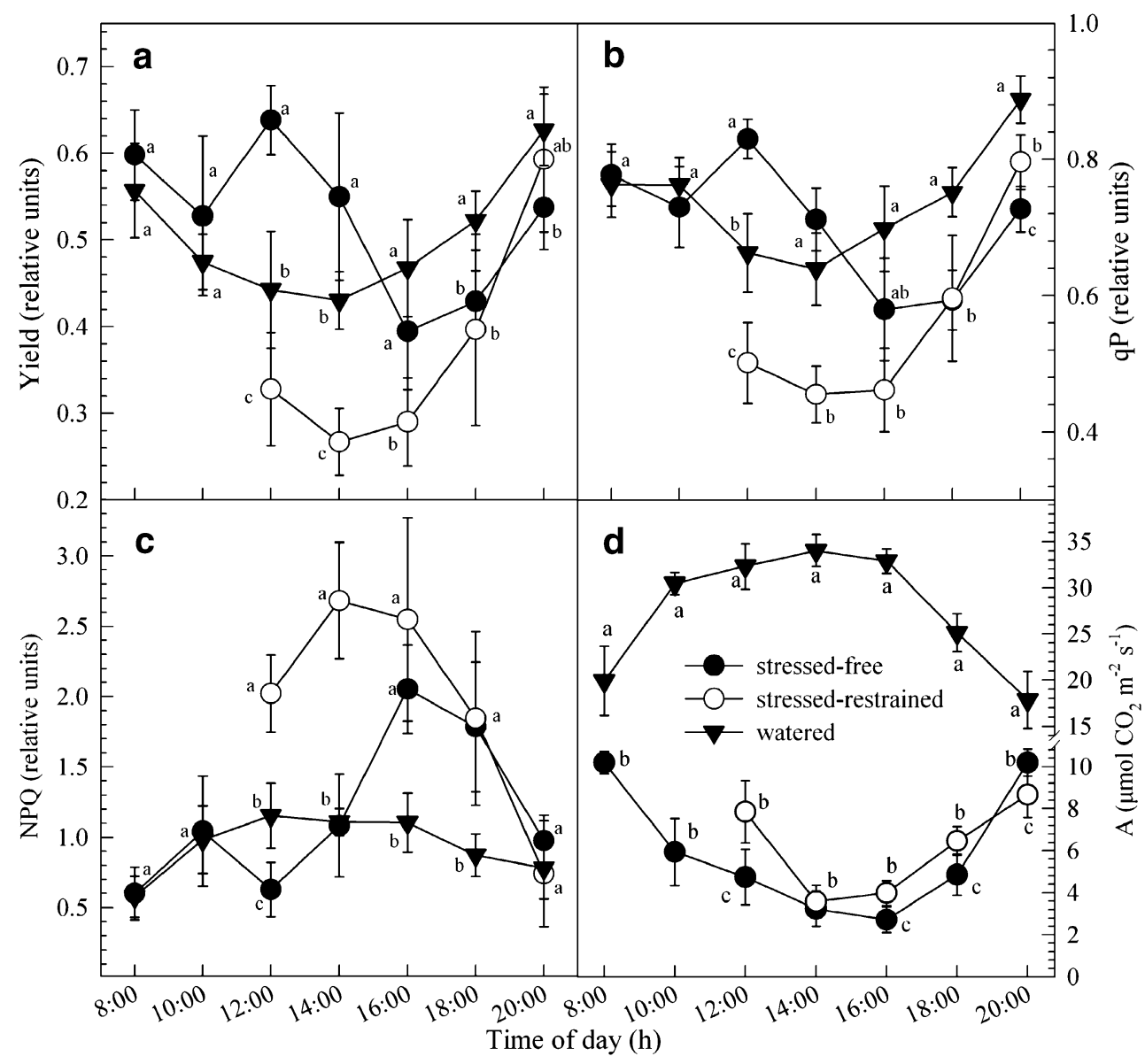

Predawn $F_{\mathrm{v}} / F_{\mathrm{m}}, \mathrm{CO}_{2}$ Assimilation Rates, and $C_{\mathrm{i}} / C_{\mathrm{a}} 4$ Days After the Wilted Leaves had been Restrained

As shown in Fig. 7, predawn $F_{\mathrm{v}} / F_{\mathrm{m}}$ in the stress-free leaves remained at about 0.84 . However, a signifcantly lower predawn $F_{\mathrm{v}} / F_{\mathrm{m}}$ value $(0.59)$ was observed in the stressrestrained leaves.

As expected, $\mathrm{CO}_{2}$ assimilation rates and $C_{\mathrm{i}} / C_{\mathrm{a}}$ in the stress-free leaves were significantly higher and lower than that in the stress-restrained leaves, respectively (Fig. 7).

\section{Discussion}

Leaf Wilting Movement Reduced the Light Incident on Leaves and their Heat Load, Thereby Alleviates Damage from Photoinhibition

Leaf movement, or diaheliotropism, to maximize the capture of sunlight during the day is well known in cotton (Lang 1973; Ehleringer and Hammond 1987). As shown in Figs. 2 and 3, well-watered plants showed diaheliotropic leaf movement during the day. Water-stressed plants, however, showed the movement only in the early morning and the extent of diaheliotropic leaf movement was smaller.
When leaf water potential declined further in water-stressed plants, the leaves wilted at about 1100 hours. As expected, wilting movement significantly affected the PAR incident on leaves and leaf temperature (Fig. 4a, b). After wilting,

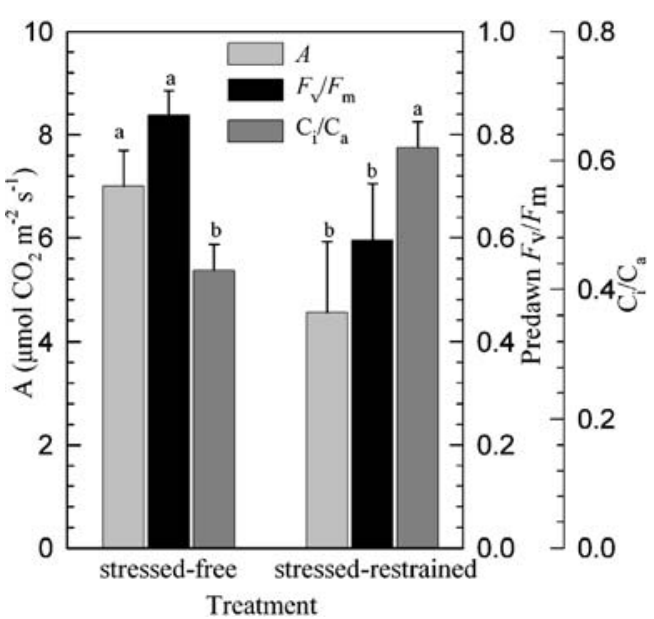

Fig. $7 \quad \mathrm{CO}_{2}$ assimilation rate (left axis), predawn $F_{\mathrm{v}} / F_{\mathrm{m}}$ (right axis) and $C_{\mathrm{i}} / C_{\mathrm{a}}$ (right offset axis) of stress-free leaves (left column) and stress-restrained leaves that had been held horizontal for 4 days (right column). Different letters indicate differences between treatments at $P<0.05$ according to Duncan's multiple range test. Bars represent the SE 
the PAR incident on leaves from water-stressed plants decreased significantly and, although it increased after 1200 hours with change in the angle of incident sunlight, the incident PAR during the day was lower. A similar phenomenon was reported in sunflower (Helianthus argophyllus L.) in an earlier study (Rawson 1979). Furthermore, when the wilted leaves were supported, they recorded greater incident light (Fig. 4a). In the case of leaf temperature, water-stressed plants, as expected, recorded higher leaf temperature (Fig. 4b). Although wilting movement reduced the light energy load, leaf temperature in stress-free leaves was consistently higher than that in wellwatered leaves. However, stress-restrained leaves recorded higher leaf temperatrue than stress-free leaves, directly demonstrating that wilting movement reduces heat load. High temperature affects photosynthesis and has been shown to intensify photoinhibition (Mamedov et al. 1993; Long et al. 1994). Therefore, wilting movement of leaves is an effective mechanism to relieve light stress and heat stress when plants are under water stress, as mentioned in earlier reviews (Begg 1980; Björkman and Demming-Adams 1994).

Values of $F_{\mathrm{v}} / F_{\mathrm{m}}$ below 0.8 generally indicate photoinhibition (Björkman and Demmig 1987). Chronic photoinhibition, the loss of PS II photochemical efficiency that results from the generation of nonfunctional centers and is slowly reversible via D1 protein synthesis (Osmond and Grace 1995), can be indicated by the parameter of predawn $F_{\mathrm{v}} / F_{\mathrm{m}}$. As shown in Fig. 5, predawn $F_{\mathrm{v}} / F_{\mathrm{m}}$ values in both well-watered and water-stressed plants were above 0.8 . However, when wilted leaves were supported horizontally for 4 days, predawn $F_{\mathrm{v}} / F_{\mathrm{m}}$ values in such leaves were significantly lower (the average value was 0.6 ; Fig. 7). It means that, under water stress, stress-restrained leaves experienced chronic photoinhibtion overnight, but stressfree leaves did not.

During the afternoon, $F_{\mathrm{v}} / F_{\mathrm{m}}$ in stress-free leaves was comparable to or only slightly lower than that in wellwatered leaves (Fig. 5), indicating that water stress did not substantially enhance the degree of photoinhibition when leaf movement was permitted. However, when wilted leaves in water-stressed plants were fixed in a horizontal position, $F_{\mathrm{v}} / F_{\mathrm{m}}$ was significantly lower compared to that in stress-free leaves. This is because the leaf wilting movement that normally lowers the PAR incident on leaves as well as leaf temperature, as discussed above, was not permitted. Wilting movement in water-stressed plants, therefore, helped to alleviate the degree of photoinhibition.

The contention that wilting movement confers protection against photoinhibition is further supported by measurements of Yield and qP (Fig. 6a, b). From 0800 to 1600 hours, Yield in stress-free leaves was higher than or comparable to that in leaves from well-watered plants; from 1600 to 2000 hours, it was lower in stress-free leaves than that in well-watered leaves because of the large decrease in PAR incident on the well-watered leaves. By comparison, when the wilted leaves were restrained, Yield was significantly decreased. A similar trend was also observed in qP (Fig. 6b). The stress-free leaves had higher qP than stress-restrained leaves due to an increase in the PAR incident on the stress-restrained leaves. It is, therefore, concluded that wilting movement in water-stressed plants helps to avoid exposure to excess light that would otherwise lead to PS II photoinhibition.

Interestingly, the patterns of variation of Yield (Fig. 6a) and $\mathrm{qP}$ (Fig. 6b) bore a striking resemblance. Given that Yield $=\mathrm{qP} \times F_{v}{ }^{\prime} / F_{m}{ }^{\prime}$, where $F_{\mathrm{v}}{ }^{\prime} / F_{\mathrm{m}}{ }^{\prime}$ is the photochemical quantum yield of open PS II centers in the light-adapted state, the resemblance of Yield and qP implies that $F_{\mathrm{v}}{ }^{\prime} / F_{\mathrm{m}}{ }^{\prime}$ was relatively constant through the day. Sailaja and Ramadas (1996) suggested that many diaheliotropic species have a characteristic ability to maintain constancy of photochemical efficiency through the day.

It is well documented that water stress enhances the dissipation of thermal energy to ensure photoprotection (Scheuermann et al. 1991; Lu and Zhang 1999; Flexas et al. 2002). Higher values of NPQ were observed in stress-free leaves, and especially in stress-restrained leaves (Fig. 6c), indicating that dissipation of thermal energy of PS II was also enhanced in water-stressed leaves as protection against photodamage.

\section{Leaf Wilting Movement Reduces Carbon Assimilation} in the Short Term but Helps to Maintain it in the Long Term

It is well known that water stress reduces $\mathrm{CO}_{2}$ assimilation rates (Chaves 1991). In this study, water-stressed plants had consistently lower $\mathrm{CO}_{2}$ assimilation rates than well-watered plants during the day (Fig. 6). Although water-stressed plants had $\mathrm{CO}_{2}$ assimilation rates in the early morning and in the late afternoon that approached those of well-watered plants, well-watered plants attained even higher $\mathrm{CO}_{2}$ assimilation rates around midday.

A striking situation occurred in stress-free and stressrestrained leaves. The protective effect of wilting movement in water-stressed leaves, as manifested in higher values of $\mathrm{qP}$ and Yield in stress-free leaves compared to that in stress-restrained leaves, did not result in higher instantaneous $\mathrm{CO}_{2}$ assimilation rates in the short term. Although the stress-restrained leaves recorded higher leaf temperature and lower Yield and $\mathrm{qP}, \mathrm{CO}_{2}$ assimilation rates in those leaves were higher than those in stress-free leaves (Fig. 6d). This is due to the stress-restrained leaves receiving more incident light energy than stress-free leaves (Fig. 4a), resulting in increased electron flow even if PS II had low photochemical efficiency (Yield). Nevertheless, in 
the long term, after 4 days of having been restrained in a horizontal position, the stress-restrained leaves recorded significantly lower steady-state $\mathrm{CO}_{2}$ assimilation rates than the stress-free leaves did (Fig. 7), indicating more severe damage to the photosynthesis apparatus. Therefore, in the long term, leaf wilting movement may help to maintain considerable carbon assimilation.

In the long-term treatment, both the predawn $F_{\mathrm{v}} / F_{\mathrm{m}}$ and the steady-state $\mathrm{CO}_{2}$ assimilation rates (Fig. 7) decreased to a similar extent (by about $40 \%$ ) in stress-restrained leaves compared with stress-free leaves. This coincidence, however, does not necessarily mean that the $\mathrm{CO}_{2}$ assimilation rate was being limited by PS II functionality. Indeed, work with isolated intact chloroplasts (Heber et al. 1988) and leaves (Lee et al. 1999) showed that the light- and $\mathrm{CO}_{2}$ saturated photosynthetic capacity is not limited by PS II until $>40 \%$ of the PS II centers are inactivated. It is more likely that the $\sim 40 \%$ loss of predawn $F_{\mathrm{v}} / F_{\mathrm{m}}$ in stressrestrained leaves is an overestimation for the leaf tissue as a whole. Since the measured chlorophyll fluorescence signal is predominantly emitted by chloroplasts near the (adaxial) leaf surface receiving direct sunlight or measurement light, the decrease in $F_{\mathrm{v}} / F_{\mathrm{m}}$ is certainly greater than for the whole leaf tissue and does not correctly represent the loss of active PS II in the whole leaf tissue (Losciale et al. 2008). Therefore, the loss of $\mathrm{CO}_{2}$ assimilation rates, which was measured for the whole tissue, cannot be completely accounted for by the limited loss of active PS II centers in the whole tissue. Considering that $C_{\mathrm{i}} / C_{\mathrm{a}}$ in stress-restrained leaves was higher than that in stress-free leaves (Fig.7), we propose that the $\mathrm{CO}_{2}$ assimilation rate was decreased due to impairment of downstream processes, such as in the Calvin-Benson cycle (Feller et al. 1998). We note that leaf temperature reached the highest levels in stress-restrained leaves (Fig. 4b). Perhaps, over the period of 4 days, critical temperature thresholds were reached, resulting in the loss of carbon assimilation activity. If so, the most important function of leaf wilting movement during water stress may be to limit the leaf temperature to a tolerable level.

\section{The Ecophysiological Signficance of Passive Wilting Leaf} Movement in Protection of Leaves from Photoinhibition

Active paraheliotropic leaf movement, generally in leguminous species, is not universal in higher plants. This active leaf movement, responding rapidly to an unfavorable enviroment, is induced by high light, and water stress often reduces the threshold for that reponse (Koller and Shak 1990; Björkman and Demming-Adams 1994). Furthermore, this active leaf movement not only occurs in water-stressed plants but also in well-watered plants when both leaf water potential and potential photosynthetic capacity are normal (Pastenes et al. 2005; Arena et al. 2008). Thus, it seems that paraheliotropic leaf movement in response to water stress are far from a terminal action preceding senescence (Rawson 1979). Passive leaf wilting movement, on the other hand, occurs quite generally in higher plants (including leguminous species) and is induced by water stress. Futhermore, leaf wilting movement becomes apparent only after several anatomical and physiological adaptations as water stress develops (Hsiao 1973; Begg 1980). Therefore, passive wilting leaf movement seem to be a final step of morphological adaption for water-stressed leaves to mitigate not only against photoinhition, but aslo senescence (Rawson 1979); without it, the photosynthesis apparatus will be damaged, and in the extreme case, leaf will died. Indeed, we observed that wilted free leaves maintained comparable carbon assimilation capacity, whereas wilted restrained leaves died at the end of the experiment.

\section{Conclusions}

In this study, we found that the wilting movement of leaves could protect water-stressed cotton plants against photoinhibition and could maintain considerable carbon assimilation in the long term in the field. Therefore, we have provided direct evidence that passive wilting leaf movement can be a strategy of photoprotection that enables plants to survive combined high light and water stress that frequently occur together in the field.

Acknowledgements We are very grateful to Dr. Da-Yong Fan for his substantial help in this study and Dr. Shou-Ren Zhang for his valuable comments on an earlier version of this paper. We also thank Dr. Zhi-Guo Han for the technical assistance on chlorophyll fluorescence. This study was financially supported by the National Natural Science Foundation of China (grant no. 30460063), by the National Key Technology R\&D Program of China (grant no. 2007BAD44B07), and by the Open Fund of the Key Laboratory of Oasis Eco-agriculture, Xinjiang Production and Construction Group, China (grant no. 200403).

\section{References}

Arena C, Vitale L, Virzo De Santo A (2008) Paraheliotropism in Robinia pseudoacacia L.: an efficient strategy to optimise photosynthetic performance under natural enviormental conditions. Plant Biol 10:194-201

Bilger W, Björkman O (1990) Role of the xanthophyll cycle in photoprotection elucidated by measurements of light-induced absorbance changes, fluorescence and photosynthesis in leaves of Hedera canariensis. Photosynth Res 25:173-185

Begg JE (1980) Adaptation of plants to water and high temperature stress. In: Turner NC, Kramer PJ (eds) Adaptations of plants to water and high temperature stress. Wiley, New York, pp 33-42

Björkman O, Demmig B (1987) Photon yield of $\mathrm{O}_{2}$ evolution and chlorophyll fluorescence characteristics at $77 \mathrm{k}$ among vascular plants of diverse origins. Planta 170:489-504 
Björkman O, Demming-Adams B (1994) Regulation of photosynthetic light energy capture, conversion, and dissipation in leaves of higher plants. In: Schulze ED, Caldwell MM (eds) Ecophysiology of photosynthesis. Springer, Berlin, pp 17-47

Ceulemans R, Isebrands JG (1996) Carbon acquisition and allocation. In: Stettler RF, Bradshaw HD Jr, Heilman PE, Hinckley TM (eds) Biology of populus and its implication for management and conservation. NRC Research Press, Ottawa, pp 355-399

Chaves MM (1991) Effects of water deficits on carbon assimilation. J Exp Bot 42:1-16

Chiariello NR, Field CB, Mooney HA (1987) Midday wilting in a tropical pioneer tree. Funct Ecol 1:3-11

Ehleringer JR, Hammond SD (1987) Solar tracking and photosynthesis in cotton leaves. Agric For Meteorol 39:25-35

Feller U, Crafts-Brandner SJ, Salvucci ME (1998) Moderately high temperature inhibit ribulose-1, 5-bisphosphate carboxylase/oxygenase (Rubisco) activase-mediated activation of Rubisco. Plant Physiol 116:539-546

Flexas J, Bota J, Escalona MJ, Sampol B, Medrano H (2002) Effects of drought on photosynthesis in grapevines under field conditions: an evaluation of stomatal and mesophyll limitations. Funct Plant Biol 29:461-471

Genty B, Briantais JM, Baker NR (1989) The relationship between the quantum yield of photosynthetic electron transport and quenching of chlorophyll fluorescence. Biochim Biophys Acta 990:87-92

Heber U, Neimanis S, Dietz KJ (1988) Fractional control of photosynthesis by the $\mathrm{Q}_{\mathrm{B}}$ protein, the cytochrome $f / b_{6}$ complex and other components of the photosynthetic apparatus. Planta $173: 267-274$

Hsiao TC (1973) Plant responses to water stress. Annu Rev Plant Biol 24:519-570

Kao WY, Tsai TT (1998) Tropic leaf movements, photosynthetic gas exchange, leaf $\delta^{13} \mathrm{C}$ and chlorophyll a fluorescence of three soybean species in response to water availability. Plant Cell Environ 21:1055-1062

Krause GH, Weis E (1991) Chlorophyll fluorescence and photosynthesis: the basics. Annu Rev Plant Biol 42:301-313

Koller D, Shak T (1990) Light-driven movements in the solar-tracking leaf of Lupinus palaestinus Boiss. (Fabaceae). Photochem Photobiol 52:187-195

Lang ARG (1973) Leaf orientation of a cotton plant. Agric Meteorol $11: 37-51$
Lee HY, Chow WS, Hong YN (1999) Photoinactivation of photosystem II in leaves of Capsicum annuum. Physiol Plant 105:377-384

Long SP, Humphries S, Falkowski PG (1994) Photoinhibition of photosynthesis in nature. Annu Rev Plant Biol 45:633-662

Losciale P, Oguchi R, Hendrickson L, Hope AB, Corelli-Grappadelli L, Chow WS (2008) A rapid, whole-tissue determination of the functional fraction of PSII after photoinhibition of leaves based on flash-induced P700 redox kinetics. Physiol Plant 132:23-32

Lu CM, Zhang JH (1999) Effects of water stress on photosystem II photochemistry and its thermostability in wheat plants. J Exp Bot 50:1199-1206

Ludlow MM, Björkman O (1984) Paraheliotropic leaf movement in Siratro as a protective mechanism against drought-induced damage to primary photosynthetic reactions: damage by excessive light and heat. Planta 161:505-518

Mamedov M, Hayashi H, Murata N (1993) Effects of glycinebetaine and unsaturation of membrane lipids on heat stability of photosynthetic electron-transport and phosphorylation reactions in Synechocystis PPC6803. Biochim Biophys Acta 1142:1-5

Osmond CB, Grace SC (1995) Perspectives on photoinhibition and photorespiration in the field: quintessential inefficiencies of the light and dark reactions of photosynthesis. J Exp Bot 46:13511362

Oxborough K, Baker NR (1997) Resolving chlorophyll a fluorescence images of photosynthetic efficiency into photochemical and nonphotochemical components-calculation of $\mathrm{qP}$ and $F_{\mathrm{v}}{ }^{\prime} / F_{\mathrm{m}}{ }^{\prime}$ without measuring $F_{\mathrm{o}}{ }^{\prime}$. Photosynth Res 54:135-142

Pastenes C, Pimentel P, Lillo J (2005) Leaf movement and photoinhibition in relation to water stress in field-grown beans. J Exp Bot 56:425-433

Powles SB (1984) Photoinhibition of photosynthesis induced by visible light. Annu Rev Plant Biol 35:15-44

Rawson HM (1979) Vertical wilting and photosynthesis, transpiration, and water use efficiency of sunflower leaves. Funct Plant Biol 6:109-120

Sailaja MV, Ramadas VS (1996) Leaf solar tracking response exhibits diurnal constancy in photosyntem II efficiency. Environ Exp Bot 36:431-438

Scheuermann R, Biehler K, Stuhlfauth T, Fock HP (1991) Simultaneous gas exchange and fluorescence measurements indicate differences in response of sunflower, bean and maize to water stress. Photosynth Res 27:189-197 